\title{
Ocorrência de entupimento de origem biológica em sistema de irrigação por gotejamento
}

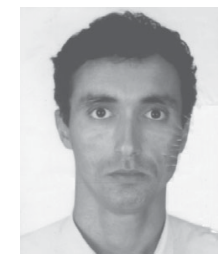

Ronaldo S. Resende ${ }^{1}$, Edivaldo Casarini ${ }^{2}$, Marcos V. Folegatti ${ }^{3}$ \& Rubens D. Coelho ${ }^{3}$

\author{
1 Departamento de Engenharia Rural da ESALQ/USP. Tel. (19) 429-4217. E-mail: rsrezend@carpa.ciagri.usp.br (Foto) \\ 2 ESALQ/USP. E-mail: mvfolega@carpa.ciagri.usp.br \\ ${ }^{3}$ Departamento de Engenharia Rural da ESALQ/USP. E-mail: rdcoelho@carpa.ciagri.usp.br
}

Protocolo $035-03 / 04 / 2000$

\begin{abstract}
Resumo: O trabalho consistiu de uma avaliação da uniformidade de distribuição de água em uma parcela de um sistema de irrigação por gotejamento para produção de flores em estufa, com 5 anos de uso, em uma propriedade no município de Atibaia, SP. Em uma amostra de 25 gotejadores retirados da parcela, determinou-se, em laboratório, a curva de vazão-pressão e o coeficiente de variação de fabricação, CV, para as pressões de 50, 100, 150, 200, 250, 300, 350 e $400 \mathrm{kPa}$. Análises química, física e de contagem bacteriológica da água foram realizadas em três pontos do sistema de irrigação: na fonte de água, após o sistema de filtragem e no final de uma linha de gotejadores no meio da parcela avaliada. O valor do CV foi de $8,2 \%$ e os valores de $73 \%$ para o coeficiente de uniformidade de aplicação de água, 97\% para o coeficiente de uniformidade hidráulica e $26 \%$ para o coeficiente de performance do emissor, juntamente com os resultados das análises da água, permitiram evidenciar-se a ocorrência de entupimento de origem biológica afetando a uniformidade de aplicação de água do sistema.
\end{abstract}

Palavras-chave: irrigação localizada, entupimento biológico, avaliação

\section{Occurrence of cloging of biological origin in drip irrigation}

\begin{abstract}
An irrigation system used for flower production during five years, in the municipality of Atibaia, SP, Brazil, was evaluated. A sample of 25 used emitters were evaluated in laboratory for discharge pressure curve and manufacturer's variation coefficient at 50, 100, 150, 200, $250,300,350$ and $400 \mathrm{kPa}$. Chemical, physical and microbiological water analysis were performed at three different points: water source, after filtration unit and at lateral end. The manufacturer's coefficient was $8.2 \%$. The statistical uniformity of the emitter discharge rates was $73 \%$; the hydraulic uniformity based on pressure distribution was $97 \%$ and the emitter performance variation was $26 \%$. Water analysis results along with performance evaluation showed occurrence of emitter cloging causing low statistical uniformity of emitter discharge.
\end{abstract}

Key words: drip irrigation, emitter cloging, uniformity evaluation

\section{INTRODUÇ̃̃O}

O município de Atibaia, no Estado de São Paulo, apresenta elevada incidência de produtores que utilizam sistemas de irrigação por gotejamento para a produção de flores em condição de campo e ambiente protegido. A avaliação de desempenho desses sistemas de irrigação não constitui rotina para a maioria dos produtores. Um dos principais problemas relacionados aos sistemas de irrigação localizados, refere-se ao potencial de entupimento dos emissores utilizados (Keller \& Bliesner, 1990) estando este problema diretamente relacionado ao pequeno diâmetro de passagem dos emissores utilizados no sistema de irrigação. Características construtivas dos emissores, físico-química e biológica da água utilizada, são também fatores a serem levados em conta para determinar o potencial de entupimento para um sistema de irrigação localizado.
As principais causas de entupimento de emissores foram reunidas por Gilbert \& Ford (1986) em três principais grupos: entupimento de origem química, física e biológica. A determinação da causa exata do entupimento de emissores, no entanto, pode ser complexa, uma vez que vários agentes na água podem interagir com outros, agravando o problema de entupimento (Ravina et al., 1992). No dimensionamento do sistema de filtragem, um dos parâmetros levados em conta é não se permitir a passagem de partículas com diâmetros maiores que $1 / 10$ e $1 / 5$ do diâmetro do orifício do emissor, para gotejadores e microaspersores, respectivamente (Keller \& Bliesner,1990). Esse parâmetro, no entanto, não é suficiente para evitar o processo de entupimento gradual de emissores. Partículas de argila, por exemplo, que comumente conseguem passar através do sistema de filtragem, embora não constituam problema por si só, podem 
sofrer processo de cimentação através de mucilagem de algas filamentosas ou bactérias, causando obstrução física em emissores (Gilbert \& Ford, 1986).

Em nossas condições, o predomínio do uso de fontes de água superficiais, aliado à alta freqüência de temperaturas na faixa ótima para o desenvolvimento de microrganismos (predominantemente algas e bactérias) resulta em um elevado risco de entupimento de origem biológica para sistemas de irrigação. $\mathrm{O}$ uso da fertirrigação, que mais que uma opção, se constitui em uma necessidade em sistemas de irrigação localizados, provê nutrientes para o crescimento adicional de bactérias no sistema de filtragem e mangueiras. Nitrogênio e fósforo fornecidos através da fertirrigação, constituem-se em dois dos principais nutrientes exigidos para o crescimento bacteriano.

Em projetos de irrigação localizada com sistemas de filtragem desenhados para alta eficiência, mas utilizando água de qualidade inferior, do ponto de vista microbiológico, observa-se que a necessidade freqüente de retrolavagem prejudica sobremaneira a sua operacionalização, principalmente para a prática de fertirrigação. Nos sistemas de irrigação do tipo localizado, o vento, que é o principal fator determinante de redução da uniformidade de aplicação em aspersão convencional e pivô-central, deixa de ser significativo. $\mathrm{O}$ entupimento de emissores resulta em variações na uniformidade de fluxo do emissor e na hidráulica da linha lateral. O entupimento de alguns emissores reduz a vazão total na linha lateral e, desta forma, reduz também a fricção total na linha, que resultará no aumento da vazão daqueles emissores não entupidos (Bralts et al.,1982) afetando duplamente a uniformidade.

Nakayama \& Bucks (1981) desenvolveram um modelo de simulação para avaliar a influência do entupimento em um sistema de irrigação por microaspersão, através do qual e com base em um coeficiente de variação de fabricação de 0,05 e no critério de permitir um Coeficiente de Uniformidade Absoluto ( $\mathrm{EU}_{\mathrm{a}}$ ) de $90 \%$, o máximo nível de entupimento tolerável seria de $2 \%$ para dois emissores por planta; de $4 \%$ para quatro emissores por planta e de $6 \%$ para oito emissores por planta. Com o uso de dois a oito emissores por planta, a uniformidade foi acentuadamente, reduzida quando 1 a $5 \%$ dos emissores se encontravam entupidos.

O tratamento de recuperação de emissores entupidos ou parcialmente entupidos, além de mais oneroso, nem sempre é efetivo; desta forma, o produtor deve avaliar cuidadosamente, antes da instalação do projeto, parâmetros de qualidade de água, qualidade do equipamento a ser adquirido, manejo do sistema a ser utilizado, além de outros, no sentido de adotar medidas preventivas para o risco de entupimento do sistema.

Este trabalho tem por objetivo avaliar a uniformidade de distribuição de água em uma parcela de um sistema de irrigação por gotejamento após 5 anos de uso, bem como a existência de processo de entupimento dos emissores utilizados.

\section{MATERIAL E MÉTODOS}

A avaliação da uniformidade de aplicação de água, seguindo-se metodologia proposta por Bralts \& Kesner (1982), foi realizada em uma parcela representativa de um sistema de irrigação por gotejamento com 5 anos de uso, em propriedade produtora de rosas (Rosa sp.), sob estufa plástica, no município de Atibaia, SP. A parcela avaliada apresentava uma área irrigada de 0,27 ha, constituída de 32 linhas de $48 \mathrm{~m}$ de comprimento cada uma e $12 \mathrm{~mm}$ de diâmetro interno, utilizando-se gotejadores da marca Netafim, modelo PCJ, autocompensante e vazão nominal de 2,0 $\mathrm{Lh}^{-1}$; os gotejadores eram espaçados $0,3 \mathrm{~m}$ na linha e $1,8 \mathrm{~m}$ entre linhas e o sistema de filtragem de água era composto por filtro de areia e de tela de 200 mesh. À entrada da parcela, uma válvula reguladora de pressão estava calibrada para resultar em uma pressão de $200 \mathrm{kPa}$. Os 16 emissores utilizados na determinação da vazão em campo, foram definidos com o sistema desligado, de modo a evitar qualquer tendência em função de aspectos visuais dos mesmos, sendo marcados com fita adesiva colorida. Para medição das vazões dos gotejadores, coletada por um período de tempo de $5 \mathrm{~min}$, foi utilizada uma proveta graduada, com precisão de $1 \mathrm{~mL}$, enquanto os dados de pressão foram obtidos após a coleta dos volumes, retirando-se o gotejador localizado imediatamente ao lado do gotejador avaliado e utilizando manômetro tipo Bourdon novo, com precisão de $10 \mathrm{kPa}$, previamente aferido. Com base nos dados de vazão e pressão coletados, foram calculados os valores de coeficiente estatístico de uniformidade de emissão $-\mathrm{U}_{\mathrm{s}}$ (Eq. 1), coeficiente de uniformidade hidráulica $-\mathrm{U}_{\mathrm{sh}}$ (Eq. 2) e variação de performance do emissor $-\mathrm{V}_{\mathrm{pf}}$ (Eq. 3).

$$
\begin{gathered}
\mathrm{U}_{\mathrm{s}}=100\left(1-\mathrm{V}_{\mathrm{qs}}\right) \\
\mathrm{Ush}_{\mathrm{sh}}=100(1-\mathrm{xVh}) \\
\mathrm{V}_{\mathrm{pf}}=100\left(\sqrt{\mathrm{V}_{\mathrm{qs}}{ }^{2}-\mathrm{x}^{2} \mathrm{Vh}^{2}}\right)
\end{gathered}
$$

$$
\begin{array}{cc}
\text { em que: } & \\
\mathrm{V}_{\mathrm{qs}} \quad & \text { coeficiente estatístico de variação de descarga } \\
& \text { dos emissores, calculado pela relação entre o } \\
& \text { desvio-padrão dos valores de vazão individual dos } \\
& \text { emissores amostrados e a média desses valores } \\
\mathrm{x} \quad \text { - expoente de descarga do emissor } \\
\mathrm{V}_{\mathrm{h}} \quad \text { - coeficiente estatístico de variação de pressão, } \\
\\
\text { calculado de forma idêntica ao } \mathrm{V}_{\mathrm{qs}} \text {, mas usando os } \\
\text { valores de pressão }
\end{array}
$$

Uma amostra de 25 emissores em uso na parcela, foi coletada do terço médio de uma lateral de irrigação, para determinação, da curva de vazão-pressão do emissor, coeficiente de variação de vazão para cada uma das pressões avaliadas e do coeficiente de descarga do emissor, no sentido de se comparar os resultados com aqueles fornecidos pelo fabricante através do catálogo do produto, para o gotejador novo. Para isso, os emissores foram conectados, espaçados de $0,3 \mathrm{~m}$, em uma linha de polietileno instalada em uma bancada de ensaio equipada com válvula reguladora de pressão, manômetro digital, com precisão de $1 \mathrm{kPa}$, e filtro de tela de 150 mesh. O tempo de coleta da vazão foi de 5 min e os volumes foram pesados em balança digital, com precisão de 0,1 g. O ensaio foi realizado no Laboratório de Irrigação do Departamento de Engenharia Rural da Escola Superior de Agricultura "Luiz de Queiroz". Foram efetuadas amostragens da água para análise química, física e contagem 
Tabela 1. Valores de vazão e pressão determinados no ensaio de uniformidade na parcela

\begin{tabular}{|c|c|c|c|c|c|c|c|c|}
\hline \multirow[t]{3}{*}{ Linha } & \multicolumn{8}{|c|}{ Posição do Gotejador na Linha } \\
\hline & \multicolumn{2}{|c|}{ Início } & \multicolumn{2}{|c|}{$1 / 4$ da Linha } & \multicolumn{2}{|c|}{$3 / 4$ da Linha } & \multicolumn{2}{|c|}{ Final } \\
\hline & $\begin{array}{l}\text { Vazão } \\
\left(\mathrm{L} \mathrm{h}^{-1}\right)\end{array}$ & $\begin{array}{c}\text { Pressão } \\
(\mathrm{kPa})\end{array}$ & $\begin{array}{l}\text { Vazão } \\
\left(\mathrm{L} \mathrm{h}^{-1}\right)\end{array}$ & $\begin{array}{c}\text { Pressão } \\
(\mathrm{kPa})\end{array}$ & $\begin{array}{l}\text { Vazão } \\
\left(\mathrm{L} \mathrm{h}^{-1}\right)\end{array}$ & $\begin{array}{c}\text { Pressão } \\
(\mathrm{kPa})\end{array}$ & $\begin{array}{l}\text { Vazão } \\
\left(\mathrm{L} \mathrm{h}^{-1}\right)\end{array}$ & $\begin{array}{c}\text { Pressão } \\
(\mathrm{kPa})\end{array}$ \\
\hline Inicial & 2,10 & 238 & 2,18 & 210 & 2,10 & 210 & 0,75 & 218 \\
\hline $2 / 4$ & 2,10 & 200 & 2,10 & 198 & 2,12 & 200 & 1,88 & 200 \\
\hline $3 / 4$ & 2,14 & 165 & 2,18 & 155 & 2,18 & 159 & 0,50 & 155 \\
\hline Final & 2,03 & 140 & 2,06 & 130 & 2,14 & 130 & 2,01 & 130 \\
\hline
\end{tabular}

bacteriológica em três pontos do sistema: fonte de captação, após sistema de filtragem e ponto final de uma linha intermediária de gotejadores. A coleta da amostra no final da linha de emissores foi efetuada após um tempo de funcionamento da parcela de $20 \mathrm{~min}$ e as amostras foram imediatamente acondicionadas em caixa térmica com gelo, e encaminhadas ao laboratório, para as análises, resultando em um tempo decorrido entre a coleta da amostra e a entrada no laboratório inferior a $3 \mathrm{~h}$.

\section{RESULTADOS E DISCUSSÃO}

Os valores de vazão e pressão amostrados na parcela avaliada, são apresentados na Tabela 1. Observa-se uma nítida tendência de redução de vazão no segmento final das linhas de irrigação, ao contrário dos demais segmentos, onde as vazões estão acima da vazão nominal do gotejador. A média das vazões determinadas foi de $1,91 \mathrm{~L} \mathrm{~h}^{-1}$, estando $4,5 \%$ abaixo da vazão nominal dos emissores. Para este conjunto de valores, o coeficiente estatístico de uniformidade de emissão, calculado através da Eq. (1), foi de $73 \%$; este valor é influenciado por todos os fatores interferentes na uniformidade, como perdas por fricção, coeficiente de variação de fabricação do emissor, topografia da área da parcela e entupimento de emissores (Bralts, 1986). Este resultado é considerado apenas regular para sistemas de irrigação localizados, encontrando-se próximo à faixa de pobre desempenho (60 - 70\%), conforme classificação proposta por Bralts \& Kesner (1982). O valor para o expoente de descarga do emissor utilizado, calculado com base nos dados do ensaio de vazão-pressão, através do método matemático dos dois pontos, após 5 anos de uso, foi de 0,1 , valor $72 \%$ superior ao determinado para o emissor novo $(\mathrm{x}=0,058)$. Valores do ensaio de vazão-pressão e curva de performance do emissor em uso, são apresentados na Tabela 2 e na Figura 1, respectivamente. Na Figura 1, esses valores são comparados àqueles citados pelo fabricante, para o emissor novo.

Tabela 2. Ensaio de vazão-pressão do emissor

\begin{tabular}{cccc}
\hline \multirow{2}{*}{$\begin{array}{c}\text { Pressão } \\
(\mathrm{kPa})\end{array}$} & \multicolumn{2}{c}{ Vazão $\left(\mathrm{L} \mathrm{h}^{-1}\right)$} & CV Após \\
\cline { 2 - 3 } & Emissor Novo & Após 5 Anos & 5 Anos \\
\hline 50 & 1,94 & 2,24 & 3,36 \\
100 & 1,92 & 2,22 & 6,81 \\
150 & 1,99 & 2,20 & 8,01 \\
200 & 2,00 & 2,19 & 8,72 \\
250 & 2,01 & 2,23 & 9,58 \\
300 & 2,04 & 2,28 & 9,84 \\
350 & 2,02 & 2,29 & 9,89 \\
400 & 2,02 & 2,30 & 9,90 \\
& & CV médio: & 8,2 \\
\hline
\end{tabular}

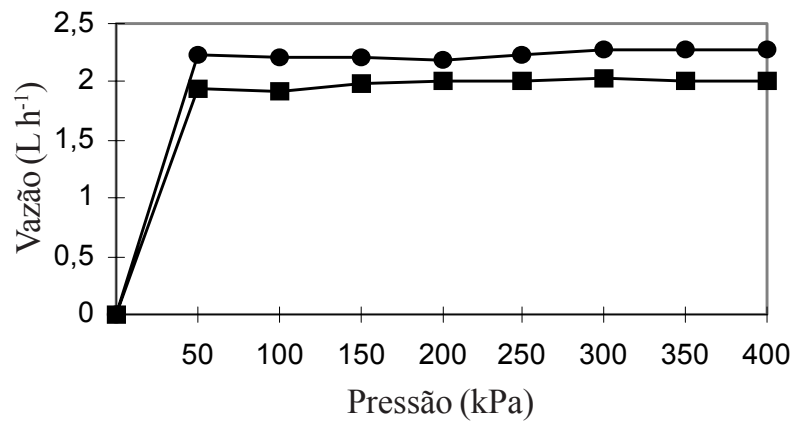

$\longrightarrow-$ Novo $\longrightarrow-5$ anos

Figura 1. Curva de vazão-pressão para o gotejador novo (dados do fabricante) e o emissor com 5 anos de uso

A parcela de irrigação apresenta declividade média de $20 \%$ no sentido da linha terciária, o que explica as altas diferenças de pressão entre as linhas de gotejadores amostradas, as quais apresentam, de modo geral, declividade leve $(<1 \%)$. O coeficiente de uniformidade hidráulica, o qual mostra o efeito da variação de pressão na uniformidade de aplicação de água (Smajstrla et al., 1998) calculado através da Eq. (2) foi de 97\%, considerando-se o expoente de descarga atual. $\mathrm{O}$ alto valor de $\mathrm{U}_{\mathrm{sh}}$ se deve ao baixo valor do expoente de descarga do emissor, o qual consegue, deste modo, não apresentar variação de vazão dentro de determinada faixa de variação de pressão, quer seja ocasionada por influência da topografia no interior da parcela ou por perdas de carga distribuída e localizada nas mangueiras. A perda de carga ao longo da linha lateral, calculada através da fórmula de Blasius, foi de $25 \mathrm{kPa}$, e com base no expoente de descarga do emissor calcula-se, através da relação $h_{1} / h_{2}=\left(\mathrm{q}_{1} / \mathrm{q}_{2}\right)^{1 / x}$, que o gotejador permite uma variação de pressão de até $260 \%$, para resultar em uma variação de vazão de $10 \%$. Desta forma, as condições topográficas da parcela e as perdas de carga na lateral de irrigação não são determinantes para o valor de $\mathrm{U}_{\mathrm{s}}$, como pode ser observado na Tabela 1, em que as pressões medidas ao longo das laterais não variam de maneira significativa.

Através da Eq. (3), proposta por Bralts \& Kesner (1982) determinou-se uma variação de performance do emissor, de $26 \%$. Para sistemas bem desenhados e recentemente instalados este valor estaria próximo ao valor do coeficiente de fabricação do emissor (Smajstrla et al., 1998) que, no caso do emissor utilizado, seria abaixo de 3\%. Pizarro (1996) aponta que o valor deste coeficiente deve encontrar-se abaixo de $20 \%$; a combinação de um valor relativamente baixo de uniformidade estatística de descarga, aliado aos altos valores de uniformidade hidráulica e ao coeficiente de variação de performance do emissor, sugere que a baixa uniformidade de aplicação de água pelo sistema está relacionada a problemas de desempenho do emissor 
utilizado. Uma vez que o emissor possui um baixo coeficiente de variação de fabricação, este baixo desempenho esta mais provavelmente relacionado ao processo de entupimento de emissores.

A determinação da curva de vazão-pressão efetuada com amostra de 25 gotejadores em uso, evidenciou aumento das vazões médias para todos os valores de pressão avaliados, conforme pode ser visto na Tabela 2 e na Figura 1, variando de $2,0 \mathrm{Lh}^{-1}$, no emissor novo, para 2,2 $\mathrm{L} \mathrm{h}^{-1}$, para o emissor após 5 anos de uso, correspondendo a um incremento médio de $10 \%$. O mesmo comportamento pôde ser observado nas vazões do gotejadores amostrados nos segmentos inicial, $1 / 4$ da linha $\mathrm{e}^{3 / 4}$ da linha, determinados em campo (Tabela 1). O aumento de vazão em função do tempo de uso do emissor é provável estar relacionado a uma deterioração da membrana flexível do emissor. Ravina et al. (1992) observaram, com uso de água residuária, aumento de vazão em emissores com e sem compensação de pressão, sendo que os primeiros se mostraram mais propensos ao fenômeno, tendo atribuído o fato à falha da membrana flexível, seja por ação de químicos aplicados na água ou por atividade microbiana. Uma vez que os gotejadores utilizados para determinação da curva de vazão-pressão foram oriundos de pontos diversos da parcela, esse aumento não deve ser contraposto a ocorrência de entupimento, o qual foi localizado no segmento final da linha lateral.

O valor médio do coeficiente de variação encontrado para o emissor após 5 anos de uso, foi de 8,2\% (Tabela 2), o que resulta em aumento de $5 \%$ em relação ao anunciado pelo fabricante para o emissor novo, o qual é inferior a $3 \%$. Somente sob pressão de serviço de $50 \mathrm{kPa}$ o $\mathrm{CV}$ foi idêntico ao emissor novo; contribuíram para o aumento do valor do CV, nas demais pressões avaliadas, dois gotejadores, os quais apresentaram, somente nessas pressões, vazões, em média, 20\% superiores aos demais, sugerindo falha da membrana responsável pela propriedade de autocompensação de pressão. Optou-se por não desconsiderar esses gotejadores dado a impossibilidade de determinar-se tratar de falha de origem ou em função do uso; uma vez não se levando em conta tais gotejadores, o CV médio seria próximo a $3 \%$, ou seja, idêntico ao emissor novo.

Os resultados das análises químicas, física e bacteriológica das amostras retiradas na captação da água, após o sistema de filtragem e final de uma linha de gotejadores em posição intermediária da parcela, encontram-se na Tabela 3, na qual se observa que os teores de cálcio, enxofre e manganês, principais elementos químicos causadores de entupimento em irrigação localizada, encontram-se em concentrações consideradas de pouco risco de entupimento de emissores, conforme quantificação proposta por Nakayama \& Bucks (1980), citados por Gilbert \& Ford (1986). Pequenos aumentos nos teores de nitrato, potássio, magnésio, supõe-se estarem mais relacionados à resíduos da fertirrigação que a processos de acumulação. A concentração do íon ferro, de $0,3 \mathrm{mg} \mathrm{L}^{-1}$, encontra-se pouco acima de valores considerados como de risco para formação de precipitados. Algumas bactérias filamentosas, como Gallionella e Leptotrhix, oxidam $\mathrm{Fe}^{+2}$, transformando-o em $\mathrm{Fe}^{+3}$ que pode precipitar-se (Pizarro, 1996). English (1985) relata que problemas com interações bactéria-ferro têm ocorrido com concentrações de ferro tão baixa quanto $0,1 \mathrm{mg} \mathrm{L}^{-1}$. Teores deste íon superiores
Tabela 3. Resultados de análise física, química e bacteriológica em diversos pontos de amostragem

\begin{tabular}{lccll}
\multicolumn{1}{c}{ Parâmetro } & Unidade $^{*}$ & $\begin{array}{c}\text { Fonte } \\
\text { d'Água }\end{array}$ & $\begin{array}{c}\text { Após } \\
\text { Filtro }\end{array}$ & $\begin{array}{c}\text { Final de } \\
\text { Linha }\end{array}$ \\
\hline $\begin{array}{l}\text { Físicos } \\
\text { Sedimentos }\end{array}$ & $\mathrm{mg} \mathrm{L}^{-1}$ & 10,3 & 16,0 & 19,7 \\
Turbidez & $\mathrm{UNT}$ & 18 & 10 & 15 \\
$\begin{array}{l}\text { Dureza Total } \\
\text { Químicos }\end{array}$ & $\mathrm{mg} \mathrm{L}^{-1}$ & 9,2 & 12,1 & 12,2 \\
Alcalinidade & $\mathrm{mg} \mathrm{L}^{-1}$ & 1,5 & 1,7 & 2,1 \\
pH & & 6,3 & 6,5 & 6,6 \\
Cloreto & $\mathrm{mg} \mathrm{L}^{-1}$ & 3,5 & 3,5 & 3,5 \\
Nitrato & $\mathrm{mg} \mathrm{L}^{-1}$ & 1,5 & 2,0 & 1,8 \\
Sulfato & $\mathrm{mg} \mathrm{L}^{-1}$ & 2,5 & 2,5 & 3,4 \\
Fósforo & $\mathrm{mg} \mathrm{L}^{-1}$ & 0,04 & 0,01 & 0,01 \\
N-NH & $\mathrm{mg} \mathrm{L}^{-1}$ & 0,1 & 0,1 & 0,1 \\
Sódio & $\mathrm{mg} \mathrm{L}^{-1}$ & 3,5 & 4,2 & 4,0 \\
Potássio & $\mathrm{mg} \mathrm{L}^{-1}$ & 2,5 & 3,0 & 3,5 \\
Cálcio & $\mathrm{mg} \mathrm{L}^{-1}$ & 1,6 & 2,4 & 2,0 \\
Magnésio & $\mathrm{mg} \mathrm{L}^{-1}$ & 1,3 & 1,5 & 1,8 \\
Ferro & $\mathrm{mg} \mathrm{L}^{-1}$ & 0,3 & 0,3 & 0,3 \\
Cobre & $\mathrm{mg} \mathrm{L}^{-1}$ & $\mathrm{~N} . \mathrm{C}$. & $\mathrm{N} . \mathrm{C}$. & $\mathrm{N} . \mathrm{C}$. \\
Manganês & $\mathrm{mg} \mathrm{L}^{-1}$ & 0,01 & 0,01 & 0,01 \\
Zinco & $\mathrm{mg} \mathrm{L}^{-1}$ & 0,03 & 0,04 & 0,04 \\
Bion & & & &
\end{tabular}

Biológica

$\mathrm{UFC} \mathrm{mL} \mathrm{mL}^{-1} \quad 5,5 \times 10^{2} \quad 1,0 \times 10^{3} \quad 2,5 \times 10^{7}$

"UFC $\mathrm{mL}^{-1}$ : Unidades Formadoras de Colônia por $\mathrm{mL}$ de água; UNT: Unidade Nefelométrica de Turbidez

a $0,2 \mathrm{mg} \mathrm{L}^{-1}$, são considerados como de risco de entupimento. O ferro precipitado forma uma incrustação vermelha, a qual pode aderir ao PVC da tubulação e também entupir emissores (English, 1985). Cortes efetuados em mangueiras utilizadas no sistema, no entanto, não evidenciaram depósitos de precipitados visíveis. Adicionalmente, os valores das concentrações de tais elementos praticamente não diferem entre os pontos de amostragem utilizados e do mesmo modo, os teor de sedimentos apresenta-se baixo e pouco difere entre os pontos de amostragem. Os valores encontrados para contagem bacteriológica no ponto de captação do sistema, apresentam valores também considerados de pouco risco para entupimento de origem biológica, mas na coleta efetuada no final da linha de emissores observa-se que este valor se encontra bem acima daquele considerado de grau de risco elevado para entupimento por algas e bactérias, segundo a mesma quantificação de Nakayama \& Bucks (1980) citados por Gilbert \& Ford (1986). Os altos valores para contagem bacteriológica encontrados no final da linha de emissores, coincidem com a ocorrência das baixas vazões determinadas neste ponto de amostragem evidenciando a ocorrência de entupimento de origem biológica dando origem a baixa uniformidade de aplicação de água, embora não tenha sido possível analisar-se a ocorrência de formação de biofilme no orifício do emissor. Constatou-se, na avaliação de campo, que vários gotejadores situados nos finais das linhas laterais apresentavam-se totalmente obstruídos, ou seja, sem vazão.

Estes resultados concordam com Ravina et al. (1992) os quais, trabalhando com entupimento de origem biológica, encontraram que os segmentos finais das laterais de emissores tendem a apresentar maior grau de entupimento em relação ao início destas, enquanto em ensaio realizado por Boman (1995) para entupimento de origem física, o mesmo ocorreu de forma uniformemente distribuída ao longo da linha lateral. Através 
dos dados da Tabela 1, observa-se que a maior variação de vazão ocorreu na linha de gotejadores, embora a variação de pressão seja bem maior entre as linhas terciárias, demonstrando que a baixa uniformidade de emissão de água não pode ser atribuída a causa hidráulica.

\section{CONCLUSÕES}

1. A vazão e C.V. médios dos gotejadores, para as pressões ensaiados, foram aproximadamente $10 \%$ e $172 \%$ maior que para o gotejador novo, respectivamente.

2. A parcela apresentou elevado desempenho hidráulico e apenas regular uniformidade de aplicação de água, com valores de $U_{\text {sh }}$ e $U_{\mathrm{s}}$ de $97 \%$ e $73 \%$, respectivamente.

3. Os valores de vazão e pressão encontrados na amostragem, juntamente com os resultados das análises de água efetuadas, permitem concluir-se que o entupimento de origem biológica se constitui na causa mais provável da baixa uniformidade de aplicação de água da parcela de irrigação avaliada.

\section{LITERATURA CITADA}

Boman, B.J. Effects of orifice size on microsprinkler clogging rates. Transactions of the ASAE, St. Joseph, v.11, n.6, p.839-843, 1995.

Bralts, V.F. Operational principles/field performance and evaluation. In: Nakayama, F.S.; Bulks, D.A. Trickle irrigation for crop production. Amsterdam: Elsevier, 1986. cap.3, p. 216-240.
Bralts, V.F.; Kesner, C.D. Drip irrigation field uniformity estimation. Transaction of the ASAE, St. Joseph, v.26, n.5 p.1369-1374. 1982.

Bralts, V.F.; Wu, I-Pai; Gitlin, H.M. Emitter plugging and drip irrigation lateral line hydraulics. Transaction of the ASAE, St. Joseph, v.26, n.5, p.1274-1281, 1982.

English, S.D. Filtration and water treatment for micro-irrigation. In: International Drip/Trickle Irrigation Congress, 3, Fresno, 1985. Proceedings... St. Joseph: ASAE, 1985. p.50-57.

Gilbert, R.G.; Ford, H.W. Operational principles/emitter clogging. In: Nakayama, F.S.; Bulks, D.A. Trickle irrigation for crop production . Amsterdam: Elsevier, 1986. cap.3, p. 142-163.

Keller, J.; Bliesner, D.R. Sprinkler and trickle irrigation. New York: van Nostrand Reinhold, 1990. 652p.

Nakayama, F.S; Bulks, D.A. Emitter clogging effects on trickle irrigation uniformity. Transaction of the ASAE, St. Joseph, v.24, p.77-80. 1981

Pizarro, F. Riegos localizados de alta frequencia. 3ed. Madrid: Ed. Mundi Prensa, 1996. 471p.

Ravina, I.; Paz, E.; Sofer, Z.; Marcu, A.; Shisha, A.; Sagi, G. Control of emitter cloging in drip irrigation with reclaimed wastewater. Irrigation Science, New York, v.13, p.129-139, 1992.

Smajstrla, A.G.; Boman, B.J.; Haman, D.Z.; Pitts, D.J.; Zazueta, F.S. Field evaluation of microirrigation water application uniformity. Gainesville: University of Florida, Cooperative Extension Service, 1998. 8p. http://hammock.ifas.ufl.edu (26/02/1999). Bulletin 265 